\title{
REVISIONES Y REVERSOS DE RIMA DE VALLBONA: "BETO Y BETINA"
}

\author{
Debra D. Andrist \\ Baylor University
}

Revisiones y reversos de Rima de Vallbona: 'Beto y Betina' es el microtítulo de este artículo; el macrotítulo de todo el proyecto es "Femenina, feminista y fantástica." Es obvio que la obra vallboniana es femenina y feminista - y fantástica en términos de la calidad. Pero es del género fantástico también y voy a explicar por qué digo esto. Luis Leal, en la introducción a la colección de cuentos vallbonianos, Mujeres y agonías, dice que "El impostor" y "Beto y Betina" son las dos obras del fantástico en este libro. Tiene razón Leal si usamos la definición tradicional del género, algo en que se incluyen elementos del realismo mágico o de la ciencia ficción, etc. Estoy de acuerdo sobre "El impostor," en donde se confunden la realidad y el sueño. Pero tengo mis dudas sobre esta evaluación de "Beto y Betina", porque ya sabemos que químicamente hay algunos que "nacen en el cuerpo inapropiado," como los estudios médicos los describen. Pero por otra parte, mantengo que toda la obra vallboniana es del género fantástico que voy a describir.

Los adjetivos, femenino, feminista y fantástico, son aliterativos pero no se asocian inmediatamente con los conceptos que representan. De hecho, la crítica de la literatura fantástica, especialmente la ciencia ficción, cita el género como uno empleado usualmente por los autores masculinos y que ofrece principalmente el escape o diversión. Pero la literatura fantástica ofrece mucho más: una dramatización fantástica de un verdadero problema real con una solución simple que puede satisfacer al lector o no. Estos cuentos se dirigen a cuestiones eternas, o tradicionalmente a formas del mito, de la leyenda y de los cuentos de hadas, y contemporáneamente porque emplean el conocimiento convencional de una manera fantástica para crear nuevas convenciones. Esta literatura no ofrece solamente violaciones del orden natural o esperado, sino posibles reversos en términos de argumentos, temas, personajes, estilos, etc. La percepción del lector aunque la manipule el escritor. El autor guarda el espacio psíquico y verdadero para utilizar la compensación o la sustitución en términos de lo que se espera o lo que se asocia, empezando con los "datos" del sistema de símbolos tradicionales, "el equipaje cultural". Hay una reacción a las normas y más que otra cosa, esta literatura evita el aburrimiento estético y demanda otra vez la atención. Pero los cuentos deben contener lo real y lo fantástico para ser creíbles al mismo tiempo que divierten o asombran. Tradicionalmente incluyen los subgéneros: el fantástico, el absurdo, la fantasía, la ciencia ficción, el surreal y el de horror.

El género fantástico también ofrece mucho más a la mujer que espera dar voz a visiones feministas; porque trata de las cuestiones eternas y puede ofrecer una dramatización fantástica 
de un problema muy grave, con o sin solución. Y para la mujer, feminista o profesional o no, es probable que el problemas más importante trate del poder y quién lo tiene. En casi toda la literatura femenina, el poder resulta ser un tema principal, quizás escondido pero siempre presente. Para la feminista, el poder es sin duda del mayor interés. Con esta perspectiva feminista y este género, la escritora puede examinar la situación socio-política en términos de los sexos-cómo es o era, cómo debe ser o cómo será, cubre todas las posibilidades. El género fantástico, con sus posibilidades, con sus violaciones de orden y reversos, le ofrece a la feminista exactamente lo que se necesita para da voz a su visión, llamar la atención y, al mismo tiempo, hacer todo esto usando una combinación de lo real y lo fantástico para ser creíble.

Dada esta evaluación, algunos críticos mantienen que en algún nivel tal vez, todas las escritoras deban serlo del género fantástico porque las mujeres son "extranjeras" o están, a lo menos, a las márgenes del sistema de los símbolos tradicionales. Como resultado de esto, se puede decir que la literatura fantástica escrita por las mujeres se hace logarítmicamente fantástica. Las escritoras crean mitos nuevos, usando la terminología de Alice Ostricker, se hacen "revisionist mythmakers" creadoras de mitos revisados (72), porque tienen que crear todo de nuevo. Las escritoras crean mitos nuevos porque tienen que recrear todo desde la perspectiva de la mujer, en lugar de la del hombre (del hombre genérico si aún aceptamos que este término sea inclusivo). En las obras alternativas de escritoras del fantástico, la mujer puede ser una figura poderosa: mesiánica, noble guerrera, sobreviviente que se adapta eternamente; fuente de sabiduría mágica o fuerza inteligente que lucha contra el desoreden y la violencia. Al revés, lo que es tradicionalmente femenino puede ser negativo y lo que tradicionalmente se ha considerado "marimacho" puede ser positivo y por eso, aún más fantástico.

He tomado cierta "licencia crítica" con el concepto de revisionist mythmaking de Ostricker para aplicarlo a las espectativas del lector sobre el poder y los personajes, además del estilo, en este estudio. Ostricker se dirigió a la poesía en inglés; yo me dirijo a la prosa corta (el cuento). De todos modos, los conceptos son los mismos, transformation /la transformación, writing-in-code/la codificación y mirroring/mimesis el reflejo-en-el espejo/mimesis. Estos tres términos se refieren respectivamente a (1) el cambio radical de la representación de los personajes (humanos), por ejemplo, la transformación del personaje (humano) en superhumano (frecuentemente diosa), animal u objeto inanimado; (2) codificar/esconder el tema o mensaje(s) de la obra, más que nunca inventando un mundo nuevo o diferente que le sirve de alegoría; y (3) la exhibición o el desarrollo de características y/o comportamientos idénticos o similares entre los personajes, casi como si fueran gemelos. Usando estas técnicas, especialmente la de la transformación de un personaje en reflejo y espejo de él mismo, Rima de Vallbona es creadora última de mitos revisados.

Aunque no sean ni obviamente feministas ni revisionistas en los cuentos mismos, algunas escritoras emplean las tres técnicas o las combinan para escribir-en-código. Por ejemplo, el papel de la autora y la caracterización de la narradora son posibilidades para hacerlo. Así, se transforma Vallbona varias veces en los cuentos de la colección, Mujéres y agonías. Reclama no solamente el obvio papel poderoso de la autora sino el escondido papel, también poderoso, del narrador masculino en primera persona en cuentos como "Penélope en sus bodas de plata" cuando el hijo, Abelardo, nos narra la transformación de su madre, o en "El impostor", narrado por un historiador obsesionado. De esta manera, Vallbona refleja-en-el espejo los papeles al 
mismo tiempo que codifica la obsesión por el poder. Su reverso es que el narrador masculino, a pesar de sus esfuerzos y en contradicción con la tradición literaria de los activos protagonistas masculinos, no puede cumplir sus deseos. Abelardo, por ejemplo, no puede restaurar la deseada pasividad de su madre. Sus temores se hacen realidad durante la fiesta: "esto es una pesadilla, [piensa Abelardo] ella nunca habla así, en público"(17). Pero anuncia Penélope su transformación a una mujer que toma control de su propia vida, que rechaza al esposo, este hombre "cruel y egoísta."(17). En este caso, la autora anula a su propio protagonista, Abelardo (algo que se ve en la obra vallboniana, no importe el sexo del protagonista), reflejando-en-el espejo los dos papeles de autora, portavoz y narrador en términos de su sexo, además dotado de poder.

Otro cuento en el que Vallbona emplea la transformación es "El muro", de la colección, Cosecha de pescadores. Este cuento pertenece más obviamente al género fantástico en términos tradicionales. Como en "El impostor", hay una confusión entre la realidad y el pensamiento de la narradora. Empezando con una analogía entre el puchero antiguo de su casa y ella misma y sus experiencias, la narradora vieja de "El muro" se transforma en cosa. "Soy ese puchero"(77) dice, comparando sus experiencias. No emplea Vallbona la técnica de reflejar-en-espejo a la autora/el narrador, sino que enfatiza la transformación de esta narradora, incapaz de evitar el cambio. Aunque la narradora tiene una epifanía cuando se da cuenta de la realidad de su transformación, no es la epifanía eufórica de Penélope. Esta última empieza su vida de nuevo con ser activa; mientras que la vieja termina la suya pasiva, inmóvil, reintegrándose en la naturaleza, al mundo de elementos.

Pero el cuento en el que Vallbona llega a la cumbre de las revisiones y reversos, la transformación de un personaje en reflejo-en-espejo, tiene que ser "Beto y Betina" de la colección Mujeres y agonías. En todos los niveles de creación, la autora hace reversos y revisa. Por ejemplo, en al forma física del cuento hay reversos (no hay revisiones sino verdaderos reversos); la narradora, Isabel, empieza la narración en un momento de epifanía, cuando se da cuenta de la identidad de Betina/Beto, entonces establece reversos para establecer a la oposición de Beto/Betina que lleva al lector en este punto hacia Betina/Beto.

La revisión más importante es de la tradición literaria hispánica. En lugar de crear un personaje que es mujer varonil y esquiva o al menos se disfraza de hombre para cumplir sus deseos, "tipo" o arquetipo muy español especialmente en el Barroco, Vallbona nos pinta a un hombre que se convierte en mujer. Esta es una revisión muy importante de una tradición que, por ejemplo, una crítica, Melvina McKendrick, ha descrito en sus dos libros con ejemplos del tipo femenino transformado.

La otra revisión es histórica también, Edward Dudley y otros como Cesáreo Bandera y yo misma hemos déscrito el fenómeno literario hispánico de los amigos que son tan idénticos que son como gemelos, dos mitades de un ser. Pero la tradición literaria es de amigos/gemelos del mismo sexo, no como Isabel y Beto. En la mente de Isabel cuando malinterpreta el sentido de lo que dice Beto sobre su sentimiento del ser incompleto; piensa Isabel que los dos, ella y Beto, son el ying y yang, el masculino y femenino, que forman una totalidad. E imagínense la angustia de Isabel al darse cuenta de que este ying y yang ya está completado en Beto/Betina al transformarse a Betina/Beto. No cabe Isabel de ninguna manera en este círculo completo. Esta realización de Beto/Betina representa una visión en sí.

Como resultado de todas estas revisiones, nosotros, los lectores, de veras, sufrimos el despertar de nuestras vidas. Claramente los cuentos vallbonianos evitan nuestro aburrimiento y 
demandan nuestra atención de nuevo con una función del fantástico. Podría continuar con las revisiones y reversos en este cuento; por ejemplo. con la revisión de los mitos griegos o, si nos interesan las teorías freudianas, con la revisión de la envidia de la mujer que quiere ser hombre, o la revisión de las teorías jungianas sobre el ánima y el ánimus (oposiciones en términos del género/sexo) presentes en cada ser. Es suficiente decir sobre este punto que la obra de Rima de Vallbona, sumamente realista en la superficie, femenina, feminista, y fantástica, es logarítmicamente fantástica en términos de la creación de mitos revisados y los reversos de los esperados.

\section{Bibliografía}

Andrist, Debra D. 1983. "Male and female friendship in the Quijote." Cervantes. 3 (2): 156158.

Banderas, Cesáreo. 1979. "Conflictive Versus Cooperative Mimesis: A Reply to Ciriaco Morón Arroyo". Diacritics. 9(3): 62-70.

Dudley, Edward. "Boccaccio and Cervantes: Novella as Novella". Hispano-Italic Studies. 1(3): 23-40.

Ortner, Sherry y Harriet Whitehead. 1981. Sexual Meanings: The Cultural Construction of Gender and Sexuality . Cambridge: Harvard University Press.

Lauter, Estella. 1984. Women as Mythmakers: Poetry and Visual Art by Twentieth Century Women. Bloomington: Indiana University Press.

McKendrick, Melvina. 1969. "The Bandolera in Golden Age Drama: A symbol of Feminist Revolt". Bulletin of Hispanic Studies. 46(1):1-20.

1974. Woman and Society in the Spanish Drama of the Golden Age. Cambridge: Harvard University Press.

Ostricker, Alice. 1982. "The Thieves of Language:Women Poets and Revisionist Mythmaking". Signs. 8(1): 68-90.

Rabkik, Eric S. Fantastic Worlds: Myth, Tales and Stories. New York: Oxford University Press.

Vallbona, Rima Roethe de. 1988. Cosecha de Pescadores. San José, Costa Rica: Editorial Costa Rica. . 1986. Mujeres y agonías. Houston, Texas: Arte Público. 